\title{
Role of lung surfactant in phagocytic clearance of apoptotic cells by macrophages in rats
}

\author{
Liying Wang ${ }^{1}$, James F Scabilloni ${ }^{1}$, James M Antonini ${ }^{1}$, Vincent Castranova ${ }^{1}$, \\ Yon Rojanasakul ${ }^{2}$, Jenny R Roberts ${ }^{1}$, Zhuo Zhang ${ }^{2}$ and Robert R Mercer ${ }^{1}$ \\ ${ }^{1}$ Pathology and Physiology Research Branch, National Institute for Occupational Safety and Health, \\ Morgantown, WV, USA and ${ }^{2}$ Department of Basic Pharmaceutical Sciences, West Virginia University, \\ Health Science Center North, Morgantown, WV, USA
}

\begin{abstract}
Two of the common features of inflammatory lung diseases are the increased production of pulmonary surfactant and the induction of lung cell apoptosis. However, the relationship between these two events has not been addressed. To investigate the role of surfactant in pulmonary inflammation and apoptosis, we instilled natural lung surfactant (Survanta) $(1.6-12.5 \mathrm{mg}$ ) into the rat lungs and determined the number of alveolar macrophages (AMs) and apoptotic lung cells. High-dose treatments of Survanta ( $>6.25 \mathrm{mg} / \mathrm{rat}$ ) caused an increase in macrophage cell influx and lung cell apoptosis at 4 weeks post-treatment. In vitro studies using lavaged macrophages showed Survanta did not cause apoptosis. We then examined the role of Survanta on ability of macrophages phagocytizing apoptotic cells. This study demonstrated that macrophages were able to eliminate apoptotic cells more efficiently in the absence of surfactant than in its presence. In vivo, high doses of Survanta decreased the ability to clear exogenously instilled apoptotic cells or bacteria. Taken together, our results suggest that excessive accumulation of lung surfactant by Survanta treatment can impair or overwhelm the phagocytic clearance function of AMs and that this impairment may lead to increased presence of apoptotic cells in the lung and bacterial survival.
\end{abstract}

Laboratory Investigation (2006) 86, 458-466. doi:10.1038/labinvest.3700406; published online 13 March 2006

Keywords: Survanta; rat lung; apoptosis; clearance; alveolar macrophage

Lung surfactant is synthesized by alveolar epithelial type II cells and is composed of approximately $80 \%$ phospholipids, $10 \%$ proteins and $10 \%$ neutral lipids. Pulmonary surfactant exists in two major compartments in the lung: the intracellular or storage compartment in the cytoplasm of alveolar type II cells and the extracellular compartment in the alveoli and distal airways. Under normal circumstances, these two pools of surfactant are maintained relatively constant. Alveolar macrophages (AMs) and type II cells are responsible for degradation of the surfactant $t^{1,2}$ and exhibit increased lipid uptake and degradation in inflamed animal lungs. ${ }^{3}$ Many toxicants, both chemical and particulate, appear to interfere with this balance. ${ }^{4}$

Correspondence: Dr L Wang, MD, PhD, Pathology and Physiology Research Branch, National Institute for Occupational Safety and Health, 1095 Willowdale Road, Morgantown, WV 26505, USA. E-mail: lmw6@cdc.gov

Received 2 June 2005; revised 26 January 2006; accepted 30 January 2006; published online 13 March 2006
Increased production of lung surfactant has been associated with many pulmonary inflammatory disorders. For example, inhalation of asbestos causes an 11-fold increase in lung surfactant in rats. ${ }^{5}$ This effect also appears to be the pathological condition of human alveolar lipoproteinosis. ${ }^{6}$ Similarly, a variety of pharmacological agents produce an elevation of lung lipids and surfactant. ${ }^{7,8}$ In silica-exposed rats, a 53-fold increase in lung dipalmitoyl phosphatidylcholine has been observed. ${ }^{9}$ It is not known if the excess surfactant contributes to the lung injury from silica. Both intraand extracellular pools of lung surfactant are induced by silica along with an increase in lung cell apoptosis. ${ }^{4,9,10}$ It is possible that excess surfactant produces apoptotic cells and/or promotes this accumulation and thus contributes to pulmonary injury.

Apoptosis is a physiologic cell death program critical for tissue homeostasis. Abnormalities in the regulation of apoptosis have been associated with several pulmonary diseases, including acute lung injury, ${ }^{11,12}$ diffuse alveolar damage, ${ }^{13}$ idiopathic 
pulmonary fibrosis, ${ }^{14}$ and lung disorders caused by bleomycin, ${ }^{15,16}$ silica, ${ }^{17}$ endotoxin, ${ }^{18}$ and the deposition of immune complexes. ${ }^{19}$ Despite growing evidence for a role of apoptosis and lung surfactant in pulmonary disorders, the relationship between these two events is not well understood. It has been suggested that surfactant could have an inhibitory or stimulatory effect on lung cell apoptosis. Certain components of lung surfactant, such as surfactant protein-A (SP-A) and SP-D, have been reported to facilitate phagocytic clearance of dying cells and pathogens by macrophages. ${ }^{20-23}$ Increased macrophage clearance of dying or apoptotic cells would therefore reduce the number of apoptotic cells in the lung. On the other hand, excessive accumulation of lung surfactant may impair or overwhelm the phagocytic clearance function of macrophages, thus increasing the number of pulmonary apoptotic cells. Because macrophages play an important role in the clearance of both apoptotic cells and lung surfactant and are known to have limited clearance capability, we hypothesized that excessive accumulation of lung surfactant may impair the clearance of apoptotic cells. This event may lead to increased presence of apoptotic cells in the lung, which can contribute to the pathologic cascade associated with inflammatory and fibrotic lung injury. To test this hypothesis, AMs were exposed in vitro and in vivo to natural lung surfactant (Survanta), and its effects on lung cell apoptosis and the clearance of apoptotic cells and a bacterial pathogen, Listeria monocytogenes, were determined.

\section{Materials and methods}

\section{Animals and Pulmonary Administration of Survanta}

Male Brown Norway (BN/CrlBR) rats obtained from Charles River Laboratories (Wilmington, MA, USA), monitored free of viral pathogens, parasites, mycoplasmas, Helicobacter and CAR Bacillus, were used for all experiments. The rats were quarantined for at least 6 days and were kept in individually ventilated cages on Alpha-Dri virgin cellulose chips and hardwood Beta-chips as bedding, provided HEPAfiltered air, autoclaved Prolab 3500 diet, and tap water ad lib, in specific pathogen-free and environmentally controlled conditions in AAALACaccredited facilities. The rats weighed about $225 \mathrm{~g}$ on arrival and were about 11 weeks old when experiments were begun. The animals were lightly anesthetized by an intraperitoneal injection of $0.6 \mathrm{ml}$ of $1 \%$ sodium methohexital (Brevital; Eli Lilly, Indianapolis, IN, USA) and intratracheal instillations were performed with a ball-tipped 18gauge animal feeding needle. Rats were instilled intratracheally with $1 \mathrm{ml}$ sterile phosphate-buffered saline (PBS) containing various concentrations of Survanta $(0,1.6,3.2,6.25$ and $12.5 \mathrm{mg}$ per rat).
Survanta was obtained from Abbott Laboratories (Columbus, OH, USA) and was used as supplied. The product contains natural lung surfactants, including disaturated phospholipids, SP-B and SP-C.

\section{Lung Histology}

The rats were euthanized by exsanguinations under anesthesia with an intraperitoneal injection of $0.2 \mathrm{ml}$ of $260 \mathrm{mg} / \mathrm{ml}$ sodium pentobarbital (Pentosol; Med-Pharmex, Inc., Pomona, CA, USA) at 4 weeks post-treatment. The lungs were intratracheally instilled with $10 \%$ buffered formalin at an instillation pressure of $20 \mathrm{~cm} \mathrm{H} \mathrm{H}_{2} \mathrm{O}$. After measurements of fixed lung volume, the lungs were embedded in paraffin and sectioned at $5 \mu \mathrm{m}$. The sections were mounted on glass slides, deparaffinized, rehydrated and then stained with hematoxylin and eosin for light microscopic examination. Analysis of lung cell apoptosis was performed using fluorescence microscopy as described below. The total number of normal and apoptotic lung cells was quantitated in randomly sampled tissue sections using standard morphometric methods as previously described..$^{24,25}$

\section{Detection of Apoptosis}

Analysis of lung cell apoptosis was performed using a terminal deoxynucleotidyl transferase-mediated dUTP nick end-labeling (TUNEL) assay kit (Promega, Madison, WI, USA), according to the manufacturer's protocols. The assay detects fragmented DNA in apoptotic cells by catalytically incorporating fluorescein-12-dUTP at the $3^{\prime}$-OH DNA polymeric tail. ${ }^{26}$ The fluorescein-12-dUTP-labeled DNA can be visualized as a green-yellow fluorescence signal using fluorescence microscopy at the excitation and emission wavelengths of 495 and $525 \mathrm{~nm}$, respectively. Normal cells were counterstained with propidium iodide to give red nuclear fluorescence. For quantitation of cell apoptosis, a minimum of 20 views was analyzed for each sample at a magnification of $\times 200$.

\section{ELISA Assay}

The assay was performed using bronchoalveolar lavage (BAL) fluids from rats. Rat lungs were lavaged by intratracheal instillation and withdraw of $8 \mathrm{ml}$ of ice-cold $\mathrm{Ca}^{2+} / \mathrm{Mg}^{2+}$-free PBS. The lavages were centrifuged and the supernatants were collected for analysis of TNF- $\alpha$ using an ELISA assay kit (R\&D Systems, Minneapolis, MN, USA), according to the manufacturer's instruction. The sensitivity of the assays was $15 \mathrm{pg} / \mathrm{ml}$ and the coefficient of variation for the assays was $<10 \%$. 


\section{Elimination of Apoptotic Cells by Alveolar Macrophages In Vitro}

Primary AMs were isolated from rats by BAL as previously described. ${ }^{27}$ Cell counts were determined using a Coulter Multisizer II (Coulter Electronics, Hialeah, FL, USA). The cells were maintained in RPMI 1640 culture medium (Sigma, St Louis, MO, USA) containing $10 \%$ fetal bovine serum (FBS), $4 \mathrm{mg} / \mathrm{ml}$ glutamine, $100 \mathrm{U} / \mathrm{ml}$ penicillin and $100 \mu \mathrm{g} / \mathrm{ml}$ streptomycin. Naive AMs $\left(1 \times 10^{6} / \mathrm{ml}\right)$ were incubated with apoptotic cells $\left(0.5 \times 10^{6} / \mathrm{ml}\right)$ in the presence or absence of Survanta $(1 \mathrm{mg} / \mathrm{ml})$. Apoptotic cells were prepared from lavaged lung cells treated with $400 \mathrm{mM}$ of dimethyl sulfoxide (DMSO) in PBS for $12 \mathrm{~h}$. The selection of DMSO as the apoptosis-inducing agent and the concentrationduration of treatment were based on an extensive search of apoptosis-inducing agents, which determined that DMSO was capable of producing high yields of apoptotic cells with no or minimal cell necrosis, LDH release or cytokine production. ${ }^{27}$ The apoptotic cells were washed twice with culture medium and incubated with freshly isolated naive AMs. The number of apoptotic cells in each sample after various incubation times $(0,1,3,6$ and $18 \mathrm{~h}$ ) was determined by flow cytometry using the TUNEL assay kit, according to the manufacturer's protocols.

\section{Lung Clearance Studies In Vivo}

To study the role of surfactant on rat lung clearance function, rats were intratracheally instilled with specified doses of Survanta with or without apoptotic cells $\left(5 \times 10^{6} / \mathrm{ml}\right)$ or L. monocytogenes (strain 10403s, serotype 1) $\left(5 \times 10^{5} / \mathrm{ml}\right)$ in $1 \mathrm{ml}$ sterile PBS, respectively. Apoptotic cells were prepared as described above. Control animals received $1 \mathrm{ml}$ of sterile PBS, normal nonapoptotic cells, or Survanta only. At indicated times post-treatment, rats were killed and lungs were isolated. Apoptosis was determined by TUNEL on tissue sections. Bacterial cell counts were performed using lung tissue homogenates as previously described. ${ }^{28}$ Diluted lung homogenates were incubated on brain-heart infusion agar plates (Fisher, Pittsburgh, PA, USA) and L. monocytogenes colonies were counted on 3 plates/lung.

\section{Statistical Analysis}

Analysis of variance and Duncan's multiple comparison test were used to evaluate the significance between measurements. Most tests were two-sided tests. The difference of the L. monocytogenes colonies between individual groups was analyzed using the Tukey-Kramer post hoc test. Data are given as means \pm s.e. For all analyses, the criterion of significance was set at $P<0.05$.

\section{Results}

\section{Effect of Exogenous Surfactant on Lung Cell Apoptosis In Vivo}

Pulmonary surfactant has been reported to play a role in host defense against infection and inflammation by promoting phagocytosis of pathogens and dying cells by innate immune cells such as macrophages. ${ }^{21-23}$ To test whether pulmonary surfactant can promote the clearance of apoptotic cells in vivo, we treated rats intratracheally with apoptotic macrophages in the absence or presence of various doses of Survanta. The effect of Survanta administration on lung cell apoptosis was determined by TUNEL. Consistent with our previous findings, ${ }^{27}$ pulmonary administration of apoptotic cells caused an increase in lung cell apoptosis over a 4-week period (Figure 1a). Co-administration of Survanta with the apoptotic lung cells surprisingly did not have a protective effect against the induction of apoptosis. On the contrary, it increased the level of lung cell apoptosis at the high dose $(12.5 \mathrm{mg} / \mathrm{rat}$ lung) of Survanta (Figure 1a). Although significantly higher levels of lung cell apoptosis were observed in rat lungs treated with Survanta alone in a dose-dependent manner (Figure 1b), the levels were lower than that with the combination treatment with apoptotic cells plus Survanta. Treatment with PBS alone or with low doses of Survanta $(<3.2 \mathrm{mg} / \mathrm{rat}$ lung) had no significant effect on lung cell apoptosis. Morphological analysis of lung tissue sections from rats treated with Survanta alone showed an increased number of apoptotic cells including AMs, epithelial cells and neutrophils (TUNEL-positive, green fluorescent signals) at higher doses ( $\geq 6.25 \mathrm{mg} / \mathrm{rat}$ lung) at 4 -week post-treatment (Figure 1c). These results suggest that high doses of Survanta may either impair the phagocytic clearance function of the lung or may induce lung cell apoptosis, which results in an increased level of apoptotic lung cells.

\section{Effect of Exogenous Surfactant on Alveolar Macrophage Cell Number}

In addition to inducing lung cell apoptosis, pulmonary administration of Survanta alone also caused an increase in macrophage cell number when high-doses of the surfactant $(\geq 6.25 \mathrm{mg} / \mathrm{rat}$ lung) were used (Figure 2a). Treatment of the rats with PBS or low doses of Survanta had no effect on the macrophage cell number. Morphological analysis of H\&E stained lung sections showed pulmonary accumulation of macrophages in rats treated with high-doses of Survanta (Figure 2b). In treated rats, the macrophages appeared larger with numerous vacuoles characteristic of foamy or lipid-laden macrophages (Figure 2b). These results suggest that high concentrations of Survanta in the rat lung were able to induce pulmonary accumulation of macrophages and that this surfactant was taken up by the 

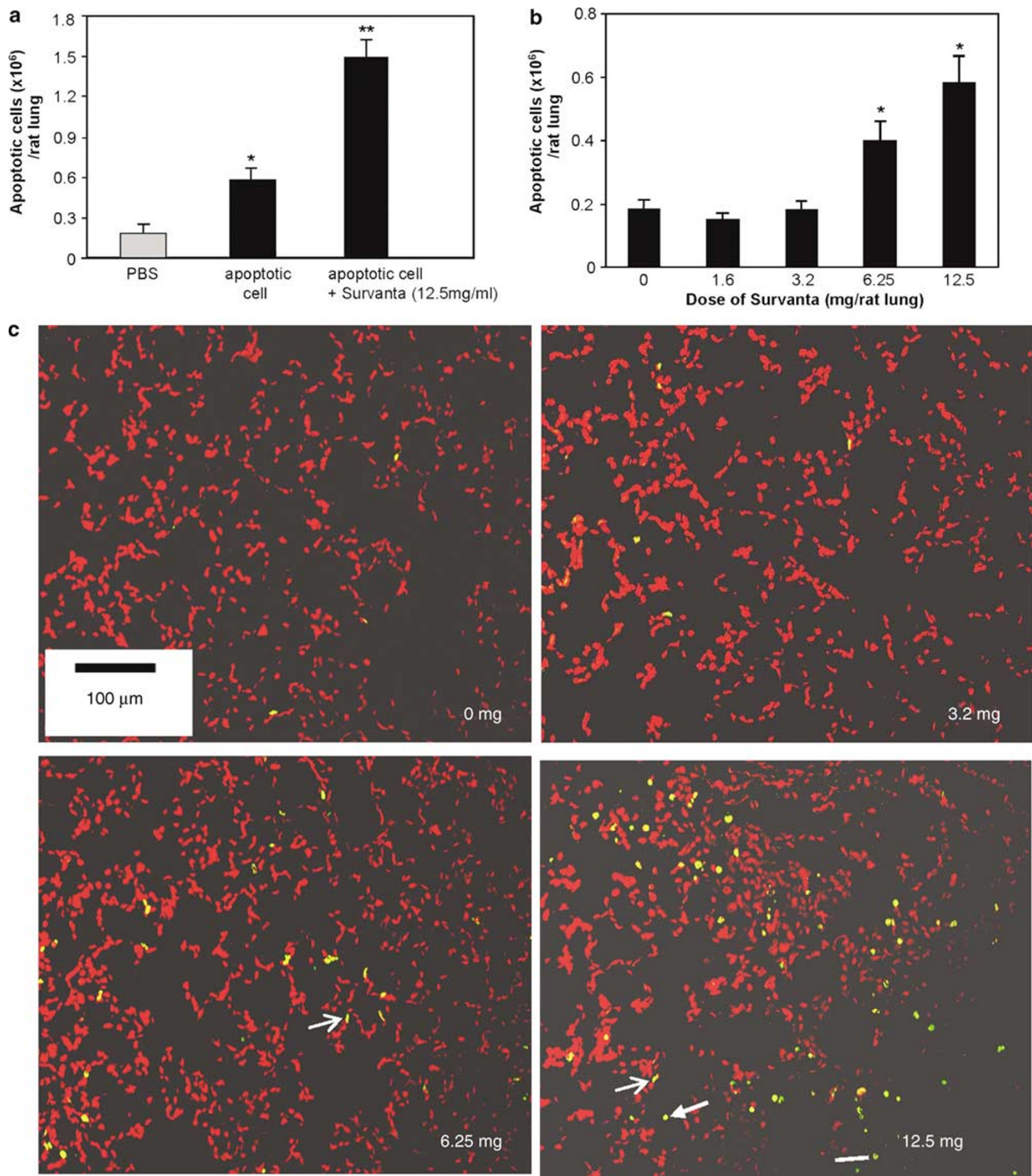

Figure 1 Effect of Survanta on lung cell apoptosis in vivo. Rats were instilled with $1 \mathrm{ml}$ of sterile PBS or Survanta at indicated concentrations in the presence or absence of apoptotic cells $\left(5 \times 10^{6}\right.$ cells/rat) as described in the Methods section. At 4 weeks posttreatment, the animals were killed and the level of lung cell apoptosis was determined by TUNEL. (a) Quantitation of TUNEL-positive lung cells in rats treated with apoptotic cells with or without Survanta. Values are means \pm s.e.; $n=4$ rats/group. ${ }^{*} P<0.05$ vs $P B S$-treated control, ${ }^{*} P<0.05$ vs apoptotic cell-treated control. (b) Rats were treated with Survanta alone at various dosing concentrations. (c) TUNEL-stained lung sections showing apoptotic cells (yellow-green fluorescence) in rat lungs treated with Survanta alone. The majority of apoptotic cells are alveolar macrophage (close arrow) plus epithelial cells (open arrow) and neutrophils (short line).

macrophages. The accumulation of macrophages in the airspaces may be due to the direct effect of Survanta or indirect effect due to inhibition of phagocytosis. Although phagocytic inhibition is likely to play a role in the accumulation process, that is, by increasing the number of un-cleared 
apoptotic cells, such increase was relatively low (Figure 1b) compared to the increase in macrophage cell number after Survanta treatment (Figure 2). a

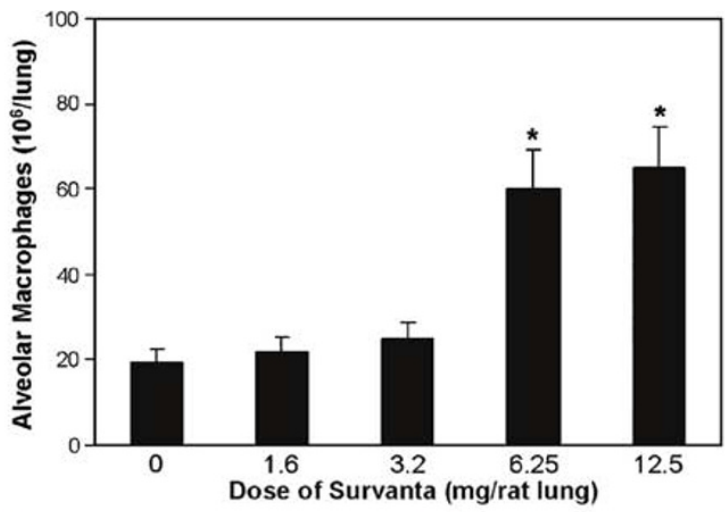

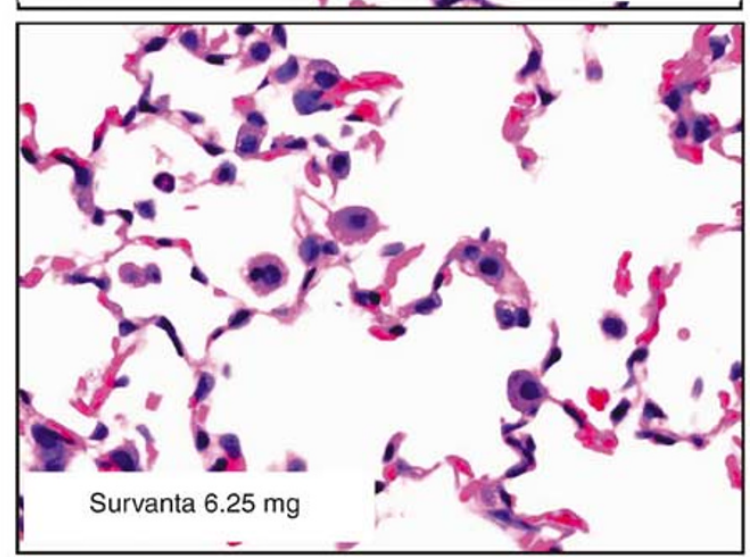

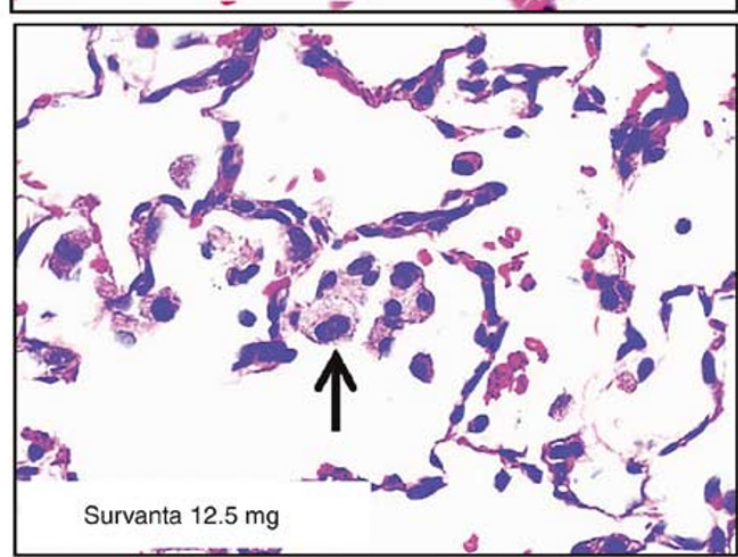

These results suggest that high-dose Survanta can directly induce pulmonary infiltration of macrophages.

\section{Effect of Survanta and Apoptotic Cell Instillation on Inflammatory Cytokine Production}

Previous studies by our group have shown that pulmonary administration of apoptotic cells caused a prolonged increase in inflammatory cytokine levels, for example TNF- $\alpha$ and TGF- $\beta$, in rat lungs. ${ }^{29}$ To test whether exogenous surfactant could affect the pulmonary inflammatory response, we treated rats intratracheally with apoptotic cells in the absence or presence of Survanta, and its effect on pulmonary TNF- $\alpha$ levels was determined by ELISA. Figure 3 shows that pulmonary instillation of apoptotic cells caused a significant increase in TNF- $\alpha$ over PBS-treated control. Co-administration of apoptotic cells with Survanta further elevated the inflammatory response. However, administration of Survanta alone had no effect on the cytokine level, suggesting that Survanta itself is non-inflammatory but has a promoting effect on lung inflammation induced by apoptotic cells.

\section{Effect of Survanta on Lung Cell Apoptosis and its Elimination In Vitro}

To determine whether exogenous surfactant can cause lung cell apoptosis directly, Survanta was added to naive lavaged lung macrophages in vitro using a known apoptosis inducer DMSO as a positive control. Figure 4 shows that treatment of lavaged cells with Survanta in vitro had no significant effect on cell apoptosis over a wide concentration range $(1-5 \mathrm{mg} / \mathrm{million} \mathrm{AM}=$ $\left.1-5 \times 10^{-6} \mathrm{mg} / \mathrm{AM}\right)$, which is higher than in vivo treatment $\left(0.6-4.8 \times 10^{-7} \mathrm{mg} / \mathrm{AM}\right)$ based on $26 \times 10^{6}$ AMs in rat lung. ${ }^{30}$ In contrast, treatment of the cells with DMSO induced substantial cell apoptosis, which was unaffected by co-incubation with Survanta even at a high dose $(5 \mathrm{mg} / \mathrm{ml})$. These results suggest that Survanta does not directly induce cell apoptosis; therefore, the promoting action of Survanta on apoptosis in vivo may be the result of interference with the phagocytic function of macrophages. To test this possibility, freshly lavaged naive macrophages were incubated with apoptotic cells,

Figure 2 Effect of Survanta on pulmonary infiltration of macrophages. Rats were instilled with PBS or Survanta at indicated concentrations. The animals were killed after 4 weeks and lung tissue sections were prepared for H\&E staining. (a) Macrophage cell count (morphometric analysis), and (b) lung morphology in control and Survanta-treated rats. Note the accumulation of lung macrophages (open arrows) with large and foamy appearance after high-dose Survanta treatments comparing to no Survanta treatment (closed arrow). Values are means \pm s.e.; $n=4$ rats/group. ${ }^{*} P<0.05$ vs PBS-treated control. 


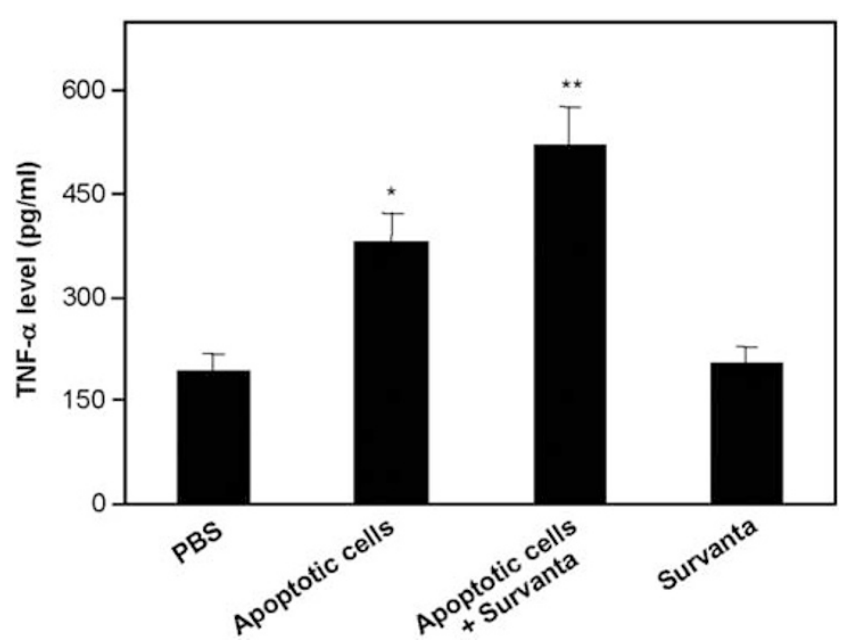

Figure 3 Effect of Survanta and apoptotic cell instillation on pulmonary TNF- $\alpha$ production. Rats were instilled intratracheally with PBS or apoptotic cells $\left(5 \times 10^{6}\right.$ cells/rat $)$ in the presence or absence of Survanta $(12.5 \mathrm{mg} / \mathrm{ml})$. The animals were killed at 4 weeks post-treatment and the lungs were lavaged for analysis of TNF- $\alpha$ by ELISA. Values are means \pm s.e., $n=4$ rats/group. ${ }^{*} P<0.05$ vs PBS-treated control, ${ }^{*} P<0.05$ vs apoptotic celltreated control.

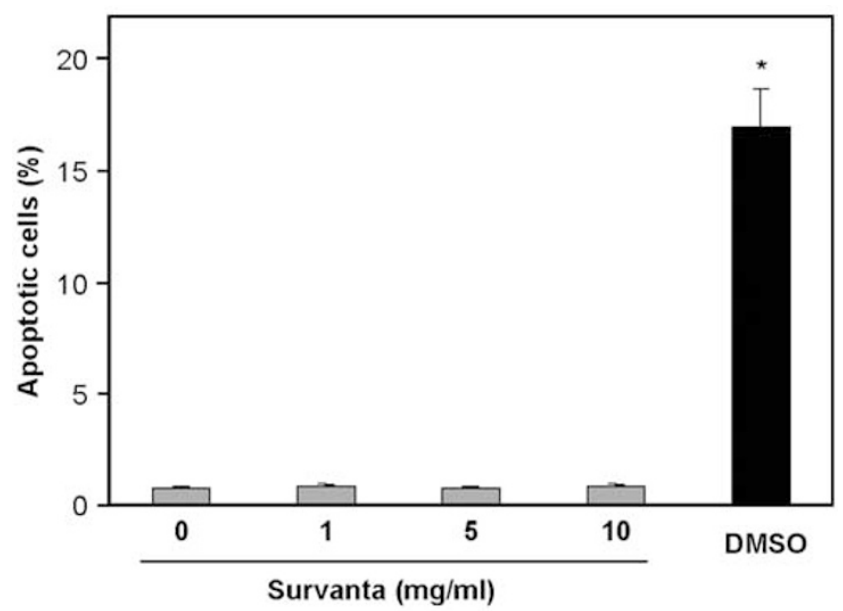

Figure 4 Effect of Survanta on lung cell apoptosis in vitro. Naive lavaged alveolar macrophages $\left(1 \times 10^{6} / \mathrm{ml}\right)$ were treated with Survanta $(0-5 \mathrm{mg} / \mathrm{ml})$ and/or DMSO $(400 \mathrm{mM})$ for $9 \mathrm{~h}$, and cell apoptosis was determined by TUNEL. Note the lack of apoptosisinducing effect of all the treated doses of Survanta. ${ }^{*} P<0.05$ vs non-treated control.

and the elimination of these apoptotic cells over time was determined in the presence or absence of Survanta. Figure 5 shows that normal macrophages were able to eliminate apoptotic macrophages in a time-dependent manner. At $6 \mathrm{~h}$ post-incubation, the number of apoptotic cells was reduced by about $70 \%$ from the initial control level. In the presence of Survanta, the number of apoptotic cells was also reduced but to a much lesser extent, that is, by approximately $25 \%$ of the control level after $6 \mathrm{~h}$ of incubation.

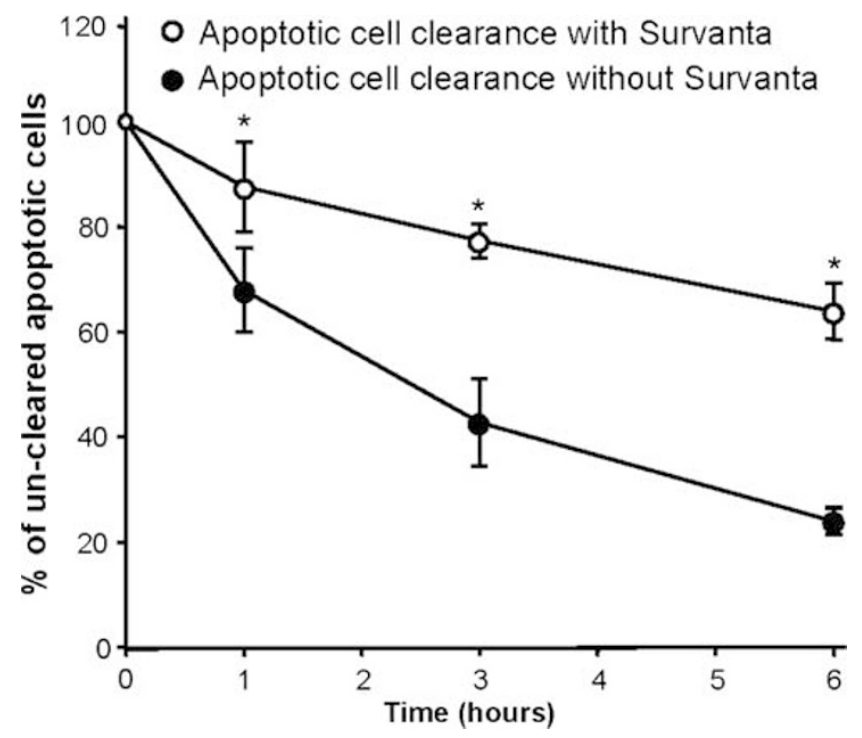

Figure 5 Effect of Survanta on apoptotic cell phagocytosis in vitro. Freshly isolated naive AMs from rats were incubated with apoptotic cells with or without Survanta $(1 \mathrm{mg} / \mathrm{ml})$. The apoptotic cells that were not eliminated by AMs were determined at indicated times. Values are means \pm s.e. from three separate experiments; $n=4$. ${ }^{*} P<0.05$ vs control without Survanta.

\section{Effect of In Vivo Survanta Treatment on Phagocytic Clearance Function of AMs}

To further investigate whether in vivo Survanta treatment could affect the phagocytic function of AMs, rats were treated with PBS or Survanta, and 1 and 4 weeks later the animals were killed and the lungs were lavaged for AMs. The AMs were then incubated with apoptotic cells, and their ability to clear these cells was assessed as earlier described. The results show that at $6 \mathrm{~h}$ post-incubation, the number of un-cleared apoptotic cells was significantly higher in Survanta-treated preparations compared to PBS-treated control, that is, 42 vs $28 \%$ at 1-week pretreatment (Figure 6). A similar finding was also observed at 4 -week pretreatment. Figure 6 also shows that pulmonary administration of Survanta with apoptotic cells further reduced the phagocytic activity of AMs against apoptotic cells.

\section{Clearance of Listeria in Rat Lungs}

To further determine the effect of Survanta on the phagocytic clearance function of the lungs, rats were intratracheally instilled with $L$. monocytogenes and its clearance in the presence or absence of Survanta was determined. In control rats treated with Listeria alone, there was a slight increase in the number of bacteria at day 3 , followed by a significant decrease at day 5 and day 7 (Figure 7a). Co-treatment of the rats with $L$. monocytogenes and Survanta $(12.5 \mathrm{mg} /$ rat lung) resulted in a significantly higher number of bacteria maintaining in the rat lungs at days 5 and 7 compared to the non-Survanta treated controls. Treatment of rats with Survanta at a lower concen- 
464

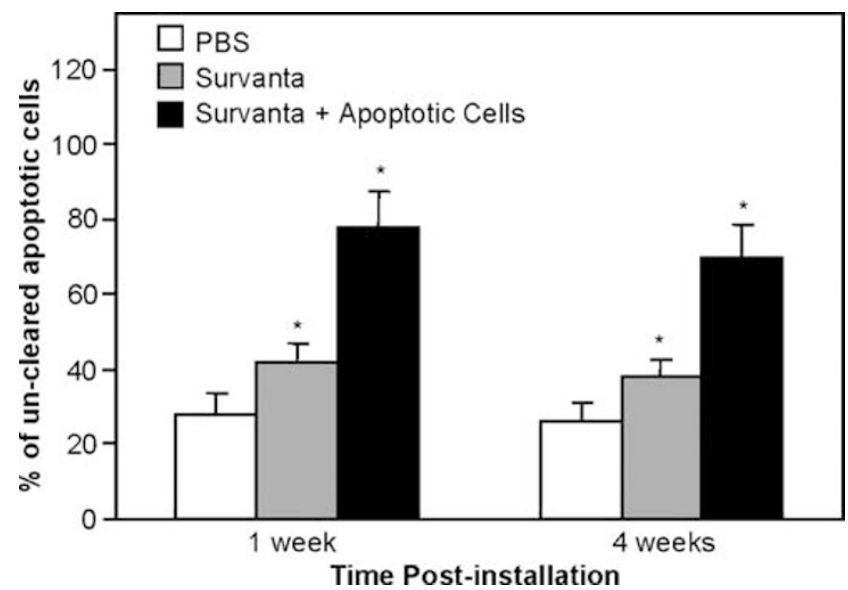

Figure 6 Effect of in vivo Survanta treatment on apoptotic cell clearance in vitro. Rats were instilled with PBS or Survanta $(12.5 \mathrm{mg} / \mathrm{ml})$ in the presence or absence of apoptotic cells $\left(5 \times 10^{6}\right.$ cells/rat). At indicated times after the treatment, the animals were killed and the lungs were lavaged to obtain AMs. The AMs $\left(1 \times 10^{6} / \mathrm{ml}\right)$ were then incubated with apoptotic cells $\left(0.5 \times 10^{6}\right)$ $\mathrm{ml}$ ) for $6 \mathrm{~h}$ and the clearance of these apoptotic cells was determined by TUNEL. Values are means \pm s.e.; $n=4$ rats/group. ${ }^{*} P<0.05$ vs PBS-treated control.

tration $(6.25 \mathrm{mg} / \mathrm{rat}$ lung) had only a marginal effect on the lung clearance of bacteria. Microscopic examination of lung tissue sections showed an increased infiltration of lung macrophages in rats treated with high-dose Survanta (Figure 7b). The macrophages appeared much larger in size and were highly foamy in appearance in rats treated with both Survanta and Listeria. These morphological changes suggest that the macrophages take up more surfactant and bacteria than they can catabolize or digest.

\section{Discussion}

Increased production of lung surfactant has been associated with certain pulmonary inflammatory disorders. In animals, pulmonary exposure to inflammatory and fibrogenic agents causes a sustained increase in lung phospholipids. ${ }^{31}$ Although the role of surfactant in the maintenance of normal lung function and in pathologic conditions has been intensively studied, its role in the clearance of apoptotic cells has not been well demonstrated. In this study, we demonstrated that pulmonary administration of Survanta is associated with an increase in lung cell apoptosis, pulmonary macrophage infiltration and a decrease in lung clearance function when used at high doses (6.25 and $12.5 \mathrm{mg} / \mathrm{rat}$ lung). The level of alveolar surfactant in rat is approximately $1.2 \mathrm{mg} /$ lung $^{31,32}$ and about 6-53 times higher in silicaexposed rats, ${ }^{9,31,32}$ which is comparable to the doses of surfactant used in our in vivo instillation study. Thus, our findings provide useful information concerning the role of elevated surfactant in pulmonary disorders with associated surfactant accumulation.

The macrophages in Survanta-treated rat lungs showed a large and foamy appearance, suggesting

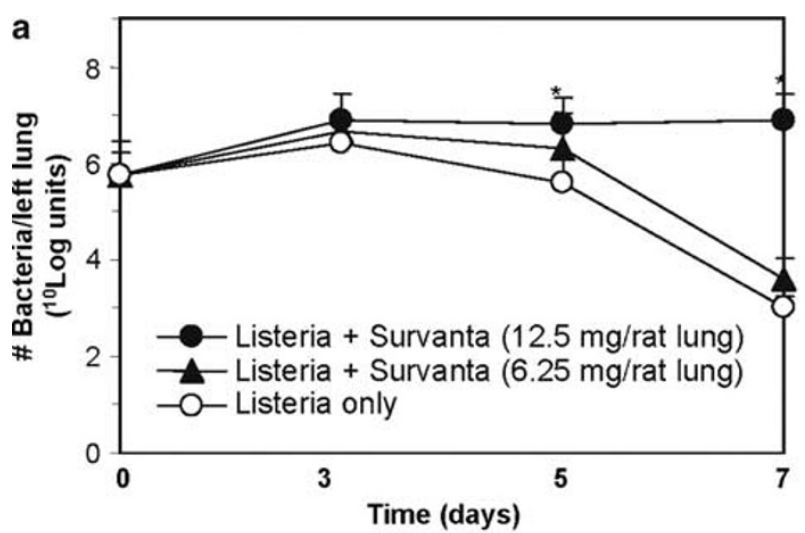

b
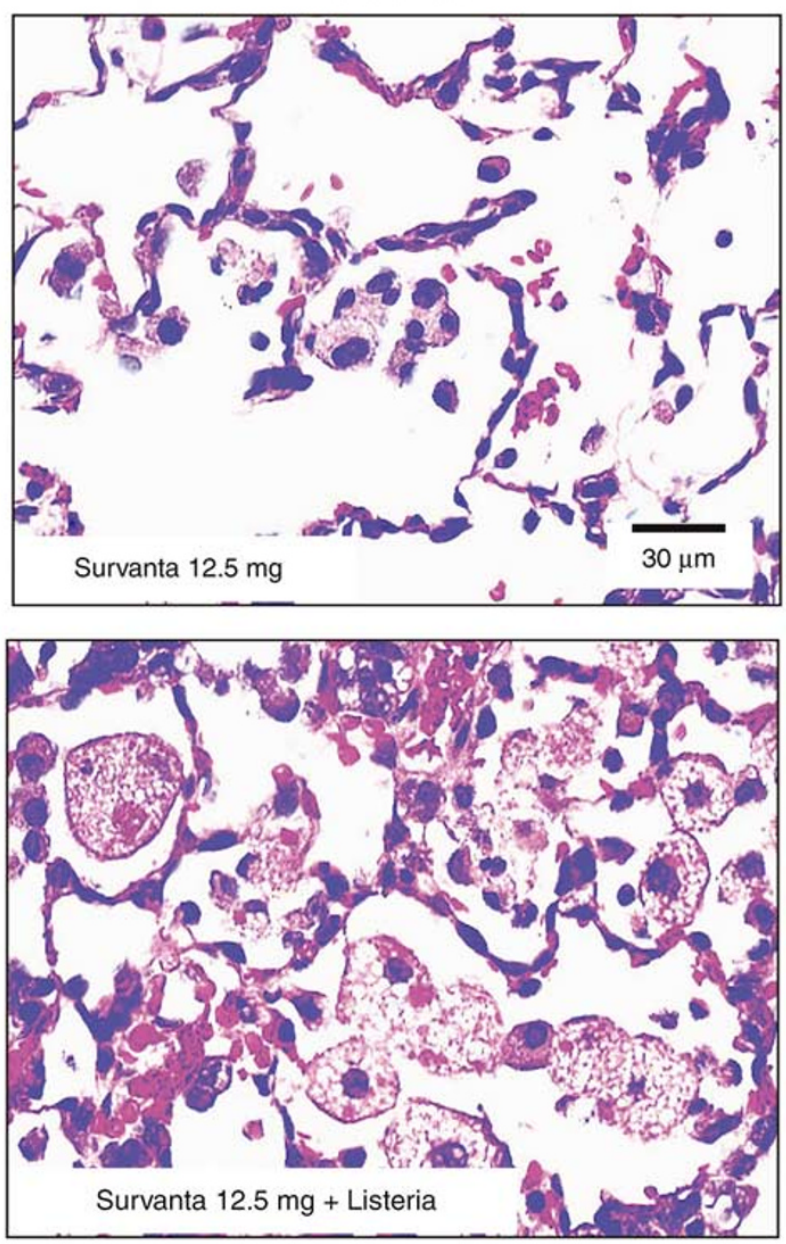

Figure 7 Effect of Survanta on lung clearance of exogenously instilled Listeria monocytogenes. Rats were inoculated intratracheally with $5 \times 10^{5}$ Listeria in $1 \mathrm{ml}$ of sterile PBS with or without Survanta (6.25 and $12.5 \mathrm{mg} /$ rat lung). At indicated times after the instillation, the animals were killed and lung tissues were prepared for bacterial cell count (a) or H\&E staining (b). (b) Representative views of lung sections from animals receiving Survanta (upper) and Survanta + Listeria (lower) are shown. Data are means \pm s.e., $n=4$ rats/group. ${ }^{*} P<0.05$ vs Listeria only group.

high levels of phagocytosis of Survanta by macrophages. These results are consistent with previous findings by Kramer et $a l,{ }^{33}$ who reported similar morphologic changes in lung macrophages after surfactant treatment, and by Eckert et $a l^{34}$ who 
observed an increased number and phagocytic activity of lung macrophages in animals treated with excess lung surfactant. These investigators suggested that an overproduction of surfactant acts as a potent stimulant for macrophage activation, which was demonstrated by increased macrophage accumulation in the lungs with increased metabolic activity. The effect of exogenous surfactant on macrophage phenotype was found to be transient. ${ }^{33}$ However, our results show that such change persisted even at 4-week post-treatment. Although these results appear contradictory, the long-term effect of surfactant treatment on macrophage phenotype has not been investigated. It is likely that differences in experimental conditions such as the type of surfactants used, animal species, and dose and time of exposure may be responsible for the observed discrepancy. It should also be noted that the observed change in macrophage morphology occurred only when highdose Survanta ( $12.5 \mathrm{mg} / \mathrm{rat}$ lung) was used, indicating that this effect was dose-dependent. High-dose Survanta treatment may overwhelm or impair the phagocytic clearance function of lung macrophages, which was demonstrated in this study.

The observation that Survanta increased lung cell apoptosis is intriguing because lung surfactant has been reported to promote phagocytic clearance of pathogens, unwanted cells and particles. ${ }^{21-23,35}$ One possible explanation for this discrepancy is that the amount of Survanta used in the present study may exceed the capacity limit of phagocytic cell clearance. Thus, only a high-dose of Survanta was able to produce apoptosis in vivo. This result is consistent with previous findings showing that lung macrophages have a limited capacity to accumulate and degrade surfactant. ${ }^{36}$ Another possible explanation is that the surfactant used in this study lacks specific protein components that promote the phagocytic activity of lung macrophages. Survanta is a natural lung surfactant that contains phospholipids and SP-B and SP-C, but not SP-A and SP-D. SP-A and SP-B have a role in regulating surface tension of the lung, whereas SP-A and SP-D have been reported to promote host defense against infection by facilitating phagocytosis of pathogens by macrophages. ${ }^{23}$ Recent in vitro studies have also indicated that SP-A and SP-D promote phagocytosis of apoptotic cells by lung macrophages. ${ }^{21}$ However, only SP-D was found to be effective in the clearance of apoptotic lung cells in vivo. SP-D deficient mice were shown to have a substantial increase in the number of apoptotic macrophages, ${ }^{22}$ supporting the role of SP-D in regulating cell apoptosis in vivo.

The increase in lung cell apoptosis by high-dose Survanta in vivo is likely to be due to an impairment of phagocytic clearance of apoptotic cells by lung macrophages. Supporting this notion are the observations that: (1) Survanta caused a dosedependent decrease in apoptotic cell elimination by macrophages (Figures 5 and 6); (2) high-dose treatment of rats with Survanta is associated with reduced clearance of intratracheally instilled Listeria (Figure 7a); and (3) macrophages in treated rat lungs were large and foamy in appearance (Figures $2 \mathrm{~b}$ and $7 \mathrm{~b}$ ), suggesting their limited capacity to catabolize the phagocytic contents. This limited phagocytic ability may also contribute to the observed increase in bacterial counts after high-dose Survanta treatment. Although excessive uptake of lung surfactant by macrophages is likely to play a key role in the reduced clearance of apoptotic cells and bacteria, other mechanisms may also be involved. These possible mechanisms include the interaction of Survanta with apoptotic cells or bacteria, which may prevent them from being recognized by macrophages. Alternatively, Survanta may interact directly with macrophages and prevent them from recognizing and phagocytizing apoptotic cells or bacteria. Our results on the presence of surfactant-ingested macrophages and their reduced ability to clear apoptotic cells, however, support the role of surfactant uptake and its impairment of the phagocytic clearance function of macrophages. Other possible mechanisms such as impairment of mucociliary transport are unlikely since such transport system normally occurs in the airways and not in the alveolar airspaces. Therefore, macrophage phagocytosis represents the major clearance mechanism in the alveolar region of the lung.

Our results also indicate that Survanta does not directly induce cell apoptosis in vitro over a wide and higher concentration range than in vivo treatment (Figure 3). In vivo, apoptotic cells are continuously generated but are effectively removed by phagocytes and neighboring cells as part of normal tissue homeostasis. The increase in lung cell apoptosis observed with high-dose Survanta in vivo might be explained by a decrease in apoptotic cell removal caused by an impairment of phagocytic clearance function of lung macrophages by the high dose of surfactant.

Based on the above findings, we conclude that excessive accumulation of lung surfactant by Survanta treatment can impair the phagocytic function of lung macrophages. Survanta does not directly induce cell apoptosis but inhibits the phagocytic function of the lung when used at high doses, which resulted in an elevated and prolonged level of apoptotic cells in the airspaces. Since excessive apoptosis has been associated with several lung disorders, the results of this study may have important implications in pulmonary surfactant therapy and in diseases whose etiology is dependent on abnormal accumulation of lung surfactant.

\section{Acknowledgements}

We thank Dr Lyndell Millecchia, Dean Newcomer, Patsy Willard and Sherri Friend for their assistance on the pathological work in this paper. 


\section{References}

1 Naimark A. Cellular dynamics and lipid metabolism in the lung. Fed Proc 1973;32:1967-1971.

2 Wright JR, Hawgood S. Pulmonary surfactant metabolism. Clin Chest Med 1989;10:83-93.

3 Quintero OA, Wright JR. Clearance of surfactant lipids by neutrophils and macrophages isolated from the acutely inflamed lung. Am J Physiol Lung Cell Mol Physiol 2002;282:L330-L339.

4 Hook GE. Alveolar proteinosis and phospholipidose of the lungs. Toxicol Pathol 1991;19:482-513.

5 Tetley TD, Hext PM, Richards KL, et al. Chrysotileinduced asbestosis: changes in the free cell population, pulmonary surfactant and whole lung tissue of rats. Br J Exp Pathol 1976;57:505-514.

6 Ramirez J, Harlan Jr WR. Pulmonary alveolar proteinosis. Nature and origin of alveolar lipid. Am J Med 1968;45:502-512.

7 Brody AR, Clay MF, Collins MM, et al. Effects of chlorphentermine hydrochloride on the surface tension properties of the rat lung. J Physiol 1975;245: 105P-106P

8 Lullmann H, Lullmann-Rauch R, Wassermann O. Druginduced phospholipidoses. II. Tissue distribution of the amphiphilic drug chlorphentermine. CRC Crit Rev Toxicol 1975;4:185-218.

9 Heppleston AG, Fletcher K, Wyatt I. Changes in the composition of lung lipids and the 'turnover' of dipalmitoyl lecithin in experimental alveolar lipoproteinosis induced by inhaled quartz. Br J Exp Pathol 1974;55:384-395.

10 Grunspan M, Antweiler H, Dehnen W. Effect of silica on phospholipids in the rat lung. $\mathrm{Br} \mathrm{J}$ Ind Med 1973;30:74-77.

11 Matute-Bello G, Winn RK, Jonas M, et al. Fas (CD95) induces alveolar epithelial cell apoptosis in vivo: implications for acute pulmonary inflammation. Am J Pathol 2001;158:153-161.

12 Bardales RH, Xie S, Schaefer RF, et al. Apoptosis is a major pathway responsible for the resolution of type II pneumocytes in acute lung injury. Am J Pathol 1996;149:845-852.

13 Guinee D, Fleming M, Hayashi T, et al. Association of p53 and WAF1 expression with apoptosis in diffuse alveolar damage. Am J Pathol 1996;149:531-538.

14 Kuwano K, Miyazaki $\mathrm{H}$, Hagimoto $\mathrm{N}$, et al. The involvement of Fas-Fas ligand pathway in fibrosing lung diseases. Am J Respir Cell Mol Biol 1999;20: 53-60.

15 Kuwano K, Hagimoto N, Kawasaki M, et al. Essential roles of the Fas-Fas-ligand pathway in pulmonary fibrosis. J Clin Invest 1999;104:13-19.

16 Kuwano K, Hagimoto N, Tanaka T, et al. Expression of apoptosis-regulatory genes in epithelial cells in pulmonary fibrosis in mice. J Pathol 2000;190:221-229.

17 Ortiz LA, Lasky J, Lungarella G, et al. Upregulation of the p75 but not the p55 TNF- $\alpha$ receptor mRNA after silica and bleomycin exposure and protection from lung injury in double receptor knockout mice. Am J Respir Cell Mol Biol 1999;16:91-101.

18 Cox G, Crossley J, Xing Z. Macrophage engulfment of apoptotic neutrophils contributes to the resolution of acute pulmonary inflammation in vivo. Am J Respir Cell Mol Biol 1995;12:232-237.
19 Nomoto Y, Kuwano K, Hagimoto N, et al. Apoptosis and Fas/Fas ligand mRNA expression in acute immune complex alveolitis in mice. Eur Respir J 1997;10:2351-2359.

20 Wright JR. Immunomodulatory functions of surfactant. Physiol Rev 1997;77:931-962.

21 Vandivier RW, Ogden CA, Fadok VA, et al. Role of surfactant proteins $\mathrm{A}, \mathrm{D}$, and $\mathrm{C} 1 \mathrm{q}$ in the clearance of apoptotic cells in vivo and in vitro: calreticulin and CD91 as a common collectin receptor complex. J Immunol 2002;169:3978-3986.

22 Clark H, Palaniyar N, Strong P, et al. Surfactant protein $\mathrm{D}$ reduces alveolar macrophage apoptosis in vivo. J Immunol 2002;169:2892-2899.

23 Wright JR. Pulmonary surfactant: a front line of lung host defense. J Clin Invest 2003;111:1453-1455.

24 Allred TF, Mercer RR, Thomas RF, et al. Brief 95\% O2 exposure effects on surfactant protein and mRNA in rat alveolar and bronchiolar epithelium. Am J Physiol 1999;276:L999-L1009.

25 Mercer RR, Russell ML, Roggli VL, et al. Cell number and distribution in human and rat airways. Am J Respir Cell Mol Biol 1994;10:613-624.

26 Gravrieli Y, Sherman Y, Ben-Sasson SA. Identification of programmed cell death in situ via specific labeling of nuclear DNA fragmentation. J Cell Biol 1992;119: 493-501.

27 Wang L, Antonini JM, Rojanasakul Y, et al. Potential role of apoptotic macrophages in pulmonary inflammation and fibrosis. J Cell Physiol 2003;194:215-224.

28 Antonini JM, Yang HM, Ma J, et al. Subchronic silica exposure enhances respiratory defense mechanisms and the pulmonary clearance of Listeria monocytogenes in rats. Inhal Toxicol 2000;12:111017-111036.

29 Wang L, Scabilloni JF, Antonini JM, et al. Induction of secondary apoptosis, inflammation and lung fibrosis after intratracheal instillation of apoptotic cells in rats. Am J Physiol Lung Cell Mol Physiol 2005 [Epub ahead of print].

30 Stone KC, Mercer RR, Gehr $\mathrm{P}$, et al. Allometric relationships of cell numbers and size in the mammalian lung. Am J Respir Cell Mol Biol 1992;6:235-243.

31 Porter DW, Ramsey D, Hubbs AF, et al. Time course of pulmonary response of rats to inhalation of crystalline silica: histological results and biochemical indices of damage, lipidosis, and fibrosis. J Environ Pathol Toxicol Oncol 2001;20:1-14.

32 Dethloff LA, Gilmore LB, Brody AR, et al. Induction of intra- and extra-cellular phospholipids in the lungs of rats exposed to silica. Biochem J 1986;233:111-118.

33 Kramer BW, Jobe AH, Ikegami M. Exogenous surfactant changes the phenotype of alveolar macrophages in mice. Am J Physiol Lung Cell Mol Physiol 2001; 280:L689-L694.

34 Eckert H, Lux M, Lachmann B. The role of alveolar macrophages in surfactant turnover. An experimental study with metabolite VIII of bromhexine (Ambroxol). Lung 1983;161:213-218.

35 Antonini JM, Reasor MJ. Effect of short-term exogenous pulmonary surfactant treatment on acute lung damage associated with the intratracheal instillation of silica. J Toxicol Environ Health 1994;43:85-101.

36 Desai R, Tetley TD, Curtis CG, et al. Studies on the fate of pulmonary surfactant in the lung. Biochem J 1978;176:455-462. 